\title{
Subjectivity Death with Dignity Recognized of Nursing Students
}

\author{
Sunyoung Jang ${ }^{1}$ and MeeSuk Wang ${ }^{2 *}$ \\ ${ }^{1,2}$ Department of Nursing, Hanseo University \\ 46 Hanseol Ro, Haemi-myun, Seosan-si, Chungcheongnam-do, 369-709, KOREA \\ ssjang@hanseo.ac.kr,mswang@hanseo.ac.kr
}

\begin{abstract}
This study was to identify the subjective attitudes on "death with dignity" perceived by nursing students, and to describe the characteristics of each category. Twenty-nine nursing students at $H$ University located in Chungcheongnam Province, Korea were asked to classify 70 statements on "death with dignity." The collected data was analyzed utilizing QUANL PC program, SPSSWIN 21.0 program. The study concluded that there were 6 types of attitudes from the nursing students towards "death with dignity." The types of attitudes towards "death with dignity" were "recognizing value in death with dignity," "inevitability of choosing death with dignity," "societal regulation of death with dignity," "death with dignity electivity," "death with dignity criteria identification" and "preparing for death with dignity." The results of this study will provide assistance for organizing a "death with dignity" education program for nursing students and establish a value system towards "death with dignity" through categorization of the nursing student attitudes. The findings will also play a crucial role in identifying the attitudes of nurses towards "death with dignity" after students become nurses and start working in various departments, possibly facing patients considering or being considered for end of life choices, including "death with dignity. Lastly this study meaning of death with dignity would be to the development well dying or death with dignity training program nursing student.
\end{abstract}

Keywords: Nursing students, Death with dignity, Q-Methodology

\section{Introduction}

\subsection{Necessity of Study}

Recently average improvement in living conditions and medical service life has increased dramatically. Elderly were increased to life with the disease in old age than to healthy living. No. 1 cause of death is cancer of the current national in south korea. Which allows the patient is not likely to welcome the regenerative dignity in death ' (welldying) Act was passed by the National Assembly plenary session. And, legislation on netting medical decisions for patients in the hospice palliative care and end-of-life process is passed 2018. Since 2018 it is possible to stop the netting care for patients with impending death. Citizens is increasing interest in the dignified death. It has become problem that life-sustaining treatment for patients with no possibility of recovery in terminal condition is a patients" right or a violation of the dignity of human beings. Socalled 'death with dignity' and/or 'withdraw of life-sustaining treatment' has emerged as a topic of another [1].

The term euthanasia ("death with dignity") has its roots in Greek: the two Greek words "eu"-meaning "good"- and "Thanatos"-meaning "death." Euthanasia therefore refers to "good death," and it is divided into two large categories of active euthanasia and passive euthanasia, according to the type of action taken leading to euthanasia. Some specialists or scholars also classify passive euthanasia as "death with dignity" [2] [3]. However, 
"death with dignity" can be conceptually differentiated from euthanasia as "death with dignity" focuses on elimination of extreme pain of a patient approaching death and aiming to preserve the dignity of the patient as a human being and enabling a dignified death. "Death with dignity" is the discontinuation of life-prolonging treatment believed to be medically pointless in enhancing quality of life or prolonging their life for a terminally ill patient as they are approaching death, whereas passive euthanasia is the shortening of a patient's life through discontinuation of treatment, nutrition supply, or drug injection which are critical to sustaining the patient's life. "Death with dignity" is not the shortening of life due to discontinuing of treatment but is a consequence of an untreatable disease [4].

In South Korea, the case of Grandmother Kim at Severance inspired the establishment of Korean Initiative for Advance Directive. Also, the article, "Decisions Regarding LifeProlonging Treatments" was published, reflecting a great social interest in dying well [5]. Also as a result of the aforementioned case, a court case regarding medical fees was brought forward and the court ruled that hospitals couldn't charge the patients for treatments that occur after the decision to discontinue life-prolonging treatments had been made (No. 2011Ga-dan62048). However, respecting the autonomous will of the patient in determining the treatment in the passing phase, and the provision of keeping accurate and detailed information on the part of the medical staff must take precedence [6]. In particular, as nurses or hospices frequently face the issue of a patient's death, they need to assist the patient and family in decision making and provide support for the patient as well as mediation and counseling [7].

For nursing students, as part of their education, it is important to identify their attitude towards "death with dignity" as they join the medical staff and need to explain the concept and the methods of euthanasia to patients at the crossroad of "death with dignity" and assist them with the process. Thus, this study attempts to identify and categorize the subjective attitude of nursing students towards "death with dignity" utilizing Q Methodology. The results will be able to assist in constructing training programs on euthanasia for nursing students and furthermore, play a crucial role in identifying the attitude of nurses who work in departments, dealing with patients in need of "death with dignity" after they become nurses.

\subsection{Purpose of the Study}

The purpose of this study was to distinguish the categories of subjective attitude of nursing students towards "death with dignity" and identify the characteristics of each type utilizing Q Methodology. This was meant to provide baseline data for proposing strategies for natural death and palliative care as part of nursing student education. The detailed aims of this study were as follows:

1) Categorize the subjective attitude of nursing students towards "death with dignity."

2) Analyze, describe and explain the characteristics of each category.

\section{Study Methods}

\subsection{Research Plan}

The aim of the study was to review the literature, media and previous studies on the topics of "death with dignity," discontinuing life-prolonging treatments and dying well, in an effort to discover and characterize the subjective categories regarding "death with dignity" used by the nursing students.

For this study, Q Statements on "death with dignity" were confirmed through in-depth interviews, literature reviews and a discussion process. Based on this, the study has applied Q Methodology in order to identify and categorize the subjectivity on the categories of attitudes of nursing students towards "death with dignity." The method 
devised by Stephenson objectively measures the attitudes or subjectivity of an individual towards a certain subject. This methodology was applied to the type of manager that one wants to work with.

\subsection{Procedure}

Selection of Q Population and Q Samples: The Q Population was deduced from among the nurses who were currently working in hospitals and students majoring in nursing at college. In order to extract comprehensive statements regarding "death with dignity," they a through review of domestic and overseas literature, open-ended questionnaires and individual in-depth interviews were performed. In order to take into account a variety of opinions that nursing students had towards "death with dignity," the data collection through open-ended questionnaires were conducted on 10 nursing students who expressed an interest to participate in the study, after being explained the purpose of the study. In order to get accurate and honest opinions of the nursing students regarding "death with dignity," the individual in-depth interviews based on the answers to the open-ended questionnaires were conducted for 20 minutes with the 10 volunteers. Through such process, a 100 Q Population was deduced. On top of this, a review of domestic and overseas literature allowed a 160 Q Population to be collected. To achieve a final set with a high level of discrimination, this 160 Q Population was analyzed by one Q Methodology specialist, 2 nursing professors, 2 nurse practitioners at general hospitals and 5 nursing students, and a final 70 Q Population was selected.

\subsection{Sampling Methods}

P Sample: Q Methodology is a qualitative research study, which emphasizes an individual's subjectivity by placing focus not on the differences between the individuals but on the differences between semanticity or importance within an individual. Since it is based on the small sample doctrine, it suggests that as a P Sample grows larger, a larger number of people become concentrated on one factor, making the characteristic less obvious or observable. As such, thus, a P Sample has a size of 50 or fewer samples. The P Sample of this study selected 29 nursing students from $\mathrm{H}$ University who agreed to participate in the study.

Q Classification: Theory of Q Methodology was utilized for Q Sample Classification, a process for distributing the extracted Q Samples to a Q Sample Distribution Table so that the results were close to a normal distribution. First, the participant read the 70 samples that were prepared and was instructed to distribute the cards according to the level of similarity between their own opinion and the read card: 1 card for very positive (score of +7 ), 2 cards for $+6,3$ cards for $+5,4$ cards for $+4,6$ cards for $+3,7$ cards for $+2,8$ cards for +1 and 8 cards for neutral (0) similarity. For cards that had the lowest level of similarities with their own opinion, the participants were instructed to distribute cards with lowest levels of similarity to their opinions: 1 card for very negative (score of -7 ), 2 cards for $-6,3$ cards for $-5,4$ cards for $-4,6$ cards for $-6,7$ cards for -2 and 8 cards for -1 . Fifteen points were allocated for a +7 score, followed by 14,13 and 12 points each. One point was allocated for a -7 score. After the Q Samples were distributed, each individual was asked to choose the cards from each end of the spectrum and record personal characteristics and the reasons for allocating those cards there. After the questionnaire, the individuals were interviewed individually on the 1 and 2 points and 14 and 15 points they distributed (on their "very negative" and "very positive" opinions, respectively)..

\subsection{Q Classification Procedure and Methods}

Q Classification process is a process in which the subjects selected as P Samples formulate voluntary definitions on the type of manager they want to work with, and classifying statements of Q Sample through a forced normal distribution method. 
After being assigned the time at which the participant was available, an appointment was made for the nursing student selected as P Sample to complete the questionnaire for data collection. Quite a few places where the participant's privacy could be ensured, such as a meeting room or a seminar room were selected by the participant for data collection, and the time of interview was negotiated for the hour most convenient for the participant so that it would not disturb their studies. Q-card was utilized for the data collection from 29 nursing students at $\mathrm{H}$ University. The time for each participant to complete $\mathrm{Q}$ Classification was 30-40 minutes on average.

\subsection{Data Analysis}

The collected data were scored and the transformed scores were attributed for each category, focusing on the cards forcefully distributed on the Q Sample distribution table: 1 point for a $-7,8$ points for neutral, 15 for a +7 , etc. The transformed scores were coded according to the Q Sample number, and processed by the QUANL PC Program with a major factor analysis. To determine the ideal number of factors, Eigen value of 1.0 was set as the standard and a range of factors was entered into the system. From this analysis, 4 types that were deemed ideal from the calculated results were finally selected.

Data analysis was performed with the QUANL PC program, and Q Factor Analysis utilized principal component factor analysis. The mean and the standard deviation of the components were calculated with SPSS WIN 21.0 Program.

\subsection{Ethical Considerations}

Prior to the study, voluntary agreement from all participants was attained and it was explained to them and their legal representatives that they were at liberty to withdraw from the study at any time. In order to respect the rights of the subjects and ensure the confidentiality of their private and personal information, all data collected for this study were processed anonymously, coded and underwent Q-sorting during the data analysis process.

\section{Results}

\subsection{Characteristics of Each Type of Nursing Managers}

3.1.1. Structure of the Categories: After Q Factor Analysis, the subjectivity of the nursing students' attitudes towards "death with dignity" via QUANL PC program, it was shown that there were 3 factors.

As displayed, Q category explains and accounts for the characteristics of each type of nursing students' attitude towards "death with dignity."

The 3 types account for $38.7 \%$ of the total variables, and the explanation power of each type was: $21.1 \%$ for Type I, $10.8 \%$ for Type II and $6.6 \%$ for Type III (Table 1). Among the 30 participants, 11 belonged in Factor 1, 13 in Factor 2 and 5 in Factor 3. In this study, the questions and the sub-questions on the 3 components of nursing manager types were not grouped together, but the components were interpreted as two separate types. It was regarded as the yin and yang that represents one of nature's properties [8]. People are grouped as one factor refers to the group that displayed similar reactions to the type of newly licensed nurses that nurses want to work with.

Table 1. Eigen Value, Variance and Cumulative Percentage

\begin{tabular}{|c|c|c|c|}
\hline Component & Type I & Type II & Type III \\
\hline Eigen Value & 6.351 & 3.254 & 2.002 \\
\hline Variance(\%) & 21.17 & 10.85 & 6.68 \\
\hline
\end{tabular}




\begin{tabular}{|c|l|l|l|}
\hline Cumulative & .2117 & .3202 & .3870 \\
\hline
\end{tabular}

The correlative coefficient between the three factors are as suggested in [Table 2]. It reflects the level of similarity between each factor; correlative coefficient between Factor 1 and Factor 2 was .088, between Factor 1 and Factor 3 was .424, between Factor 2 and Factor 3 was .869 and Factor 2 and Factor 3 displayed a relatively higher level of correlation at .869. However, the correlation between factors in Q Methodology, unlike the factor analysis methods in quantitative study, is not based on complete independence of each factors but rather focuses on discovering the factors, and therefore, factor deduction based on the level of correlation is not an issue.

Table 2. Correlations between Factors

\begin{tabular}{|c|c|c|c|}
\hline & Factor I & Factor II & Factor III \\
\hline Factor I & 1 & & \\
\hline Factor II & .088 & 1 & \\
\hline Factor III & .424 & .869 & 1 \\
\hline
\end{tabular}

3.1.2. Extraction of the type of death with dignity: In order to analyze the subjectivity of the nursing students' attitude towards "death with dignity" by category, the characteristics of each type were recorded based on statements for which nurses in each category agreed or disagreed, and the analysis was performed with a focus on items with notable differences in the value of mean and standard deviation. Also referring to the reason for the participants' choice of statements in Q Classification, sociodemographic background of the respondents and emotions experienced at work were also taken into account.

The names of the categories, connoting the characteristics of each type, were agreed upon by 5 nursing students, one doctor of literature and 2 nursing scholars based on the analyzed data and through collective discussion. Based on the 3 -factor structure, Q Reactions of $\mathrm{P}$ Sample (study participants) were classified into questions and subquestions, extracting 6 types of death with dignity.

Table 3. Q-Statements on New Nurse Images Type of Representative Items and $\mathrm{Z}$-cores $(\mathrm{N}=29)$

\begin{tabular}{|c|c|c|c|c|c|}
\hline \multicolumn{6}{|c|}{ Representative items of type } \\
\hline Factor & Type & No & Representative items & Mean (SD) & $\begin{array}{l}\text { Z- } \\
\text { score }\end{array}$ \\
\hline \multirow{7}{*}{$\begin{array}{c}\text { Factor } \\
1 \\
(\mathrm{~N}=11 \\
)\end{array}$} & \multirow{5}{*}{$\begin{array}{c}\text { Type } \\
1\end{array}$} & 56 & $\begin{array}{l}\text { "Death with dignity" should reflect } \\
\text { the will of the individual. }\end{array}$ & $\begin{array}{c}11.73 \\
(2.649)\end{array}$ & 2.16 \\
\hline & & 68 & $\begin{array}{l}\text { "Death with dignity" reduces anxiety } \\
\text { towards death as one faces pre- } \\
\text { determined death. }\end{array}$ & $\begin{array}{l}11.09 \\
(2.587)\end{array}$ & 2.16 \\
\hline & & 69 & $\begin{array}{l}\text { "Death with dignity" increases the } \\
\text { sadness of families as they say their } \\
\text { last goodbyes. }\end{array}$ & $\begin{array}{c}10.82 \\
(1.888)\end{array}$ & 1.88 \\
\hline & & 23 & $\begin{array}{l}\text { Humans have a right to choose when } \\
\text { they want to die. }\end{array}$ & $\begin{array}{c}11.64 \\
(2.014)\end{array}$ & 1.53 \\
\hline & & 53 & $\begin{array}{l}\text { "Death with dignity" maintains } \\
\text { dignity of the patient. }\end{array}$ & $\begin{array}{l}10.18 \\
(2.183)\end{array}$ & 1.38 \\
\hline & \multirow[t]{2}{*}{$\begin{array}{c}\text { Type } \\
2\end{array}$} & 34 & $\begin{array}{l}\text { Venue and facility for preparation of } \\
\text { "death with dignity" within the } \\
\text { medical institution needs to be set up }\end{array}$ & $4.18(2.750)$ & -2.32 \\
\hline & & 42 & It is the family's duty to delay death & $4.55(3.174)$ & -2.25 \\
\hline
\end{tabular}




\begin{tabular}{|c|c|c|c|c|c|}
\hline & & & and prolong life. & & \\
\hline & & 25 & Only God can intervene in death. & $4.64(3.501)$ & -1.87 \\
\hline & & 26 & $\begin{array}{l}\text { As a medical advance can improve a } \\
\text { patient's situation in a short period of } \\
\text { time, "death with dignity" should not } \\
\text { be allowed. }\end{array}$ & $5.09(2.300)$ & -1.82 \\
\hline & & 17 & $\begin{array}{l}\text { Patients from a low socioeconomic } \\
\text { class can easily choose "death with } \\
\text { dignity." }\end{array}$ & $5.27(2.328)$ & -1.66 \\
\hline \multirow{10}{*}{$\begin{array}{l}\text { Factor } \\
2 \\
(\mathrm{~N}=13 \\
\quad)\end{array}$} & \multirow{5}{*}{$\begin{array}{c}\text { Type } \\
3\end{array}$} & 3 & $\begin{array}{l}\text { Life-prolonging treatment is a } \\
\text { psychological burden on the patient } \\
\text { and the family. }\end{array}$ & $\begin{array}{c}11.54 \\
(3.503)\end{array}$ & 2.32 \\
\hline & & 2 & $\begin{array}{l}\text { "Death with dignity" according to the } \\
\text { will of a terminal patient should be } \\
\text { accepted. }\end{array}$ & $\begin{array}{l}10.15 \\
(3.955)\end{array}$ & 1.87 \\
\hline & & 9 & $\begin{array}{l}\text { Prior to permitting "death with } \\
\text { dignity," definite criteria for its } \\
\text { application must be set out. }\end{array}$ & $\begin{array}{c}11.69 \\
(2.689)\end{array}$ & 1.86 \\
\hline & & 41 & Humans have the right to be treated. & $\begin{array}{l}11.46 \\
(1.664)\end{array}$ & 1.83 \\
\hline & & 12 & $\begin{array}{l}\text { There should be support for patients } \\
\text { who give up on treatment due to } \\
\text { financial reasons. }\end{array}$ & $\begin{array}{l}11.46 \\
(2.757)\end{array}$ & 1.59 \\
\hline & \multirow{5}{*}{$\begin{array}{c}\text { Type } \\
4\end{array}$} & 39 & $\begin{array}{l}\text { "Death with dignity" enhances the } \\
\text { end-of-life experience of a terminal } \\
\text { patient }\end{array}$ & $4.64(2.631)$ & -1.93 \\
\hline & & 6 & $\begin{array}{l}\text { "Death with dignity" only } \\
\text { acknowledges medical treatment. }\end{array}$ & $4.62(2.959)$ & -1.84 \\
\hline & & 29 & $\begin{array}{l}\text { The family of the patient can choose } \\
\text { "death with dignity" even if treatment } \\
\text { is an option. }\end{array}$ & $6.31(3.987)$ & -1.41 \\
\hline & & 53 & $\begin{array}{l}\text { "Death with dignity" maintains } \\
\text { dignity of the patient. }\end{array}$ & $5.62(1.557)$ & -1.38 \\
\hline & & 52 & $\begin{array}{l}\text { One can spend the rest of their life } \\
\text { meaningfully. }\end{array}$ & $5.77(1.787)$ & -1.36 \\
\hline \multirow{6}{*}{$\begin{array}{l}\text { Factor } \\
3 \\
(\mathrm{~N}=5)\end{array}$} & \multirow{5}{*}{$\begin{array}{c}\text { Type } \\
5\end{array}$} & 2 & $\begin{array}{l}\text { "Death with dignity" according to the } \\
\text { will of a terminal patient should be } \\
\text { accepted. }\end{array}$ & $\begin{array}{c}13.60 \\
(1.140)\end{array}$ & 2.46 \\
\hline & & 9 & $\begin{array}{l}\text { Prior to permitting "death with } \\
\text { dignity," definite criteria for its } \\
\text { application must be set out. }\end{array}$ & $\begin{array}{c}13.20 \\
(1.483)\end{array}$ & 2.13 \\
\hline & & 31 & $\begin{array}{l}\text { When making the decision on "death } \\
\text { with dignity," open communication } \\
\text { between the patient, the family and } \\
\text { the medical staff is essential. }\end{array}$ & $\begin{array}{l}11.60 \\
(1.817)\end{array}$ & 1.60 \\
\hline & & 1 & $\begin{array}{l}\text { It is unfair to painfully prolong one's } \\
\text { life against their will. }\end{array}$ & $\begin{array}{l}11.00 \\
(2.915)\end{array}$ & 1.55 \\
\hline & & 8 & $\begin{array}{l}\text { Life-prolonging treatment is a large } \\
\text { financial burden on the family of the } \\
\text { patient. }\end{array}$ & $\begin{array}{c}11.80 \\
(2.588)\end{array}$ & 1.48 \\
\hline & $\begin{array}{c}\text { Type } \\
6\end{array}$ & 44 & $\begin{array}{l}\text { It is against filial duty to delay death } \\
\text { and prolong life. }\end{array}$ & $4.80(4.417)$ & -1.18 \\
\hline
\end{tabular}




\begin{tabular}{|l|c|c|c|c|c|}
\hline & 16 & $\begin{array}{c}\text { Human life has absolute sanctity and } \\
\text { discontinuing treatment cannot be } \\
\text { justified in any way. }\end{array}$ & $5.40(2.074)$ & -1.30 \\
\cline { 2 - 6 } & 25 & Only God can intervene in death. & $5.20(2.588)$ & -1.36 \\
\cline { 2 - 6 } & 63 & $\begin{array}{c}\text { If possible, no matter for how long, } \\
\text { life should be prolonged for sanctity } \\
\text { of life. }\end{array}$ & $5.00(2.345)$ & -1.44 \\
\cline { 2 - 5 } & 59 & $\begin{array}{c}\text { "Death with dignity" takes away basic } \\
\text { human rights. }\end{array}$ & $5.00(3.082)$ & -1.47 \\
\hline
\end{tabular}

3.1.3. Analysis per Type: The suggested subjective categories of nursing students' attitude towards "death with dignity" deduced through the above categorical analysis are discussed below.

Recognizing value in "death with dignity": There were 20 statements that were categorized as Type 1 (Table 3). The following are the descriptions of Q Classification interviews with nurses who displayed characteristics of this type, which assists in understanding of the nature of this type. Number $22(\mathrm{Z}=.193)$ and $29(\mathrm{Z}=1.35)$ displayed a high level of factor weight. The statements with the highest level of agreement in Type 1 were number 56 ("Death with dignity" should reflect the will of the individual) and number 68 ("Death with dignity" reduces anxiety towards death as one faces predetermined death). Thus, high scores in Factor 1 advocated a "value in having death with dignity."

Inevitability of choosing "death with dignity": There were 11 statements that were categorized as Type 2 (Table 3). The statements reflected a high level of disagreement in Type 2 and were for number 34 (Venue and facility for preparation of "death with dignity" within the medical institution needs to be set up), number 42 (It is the family's duty to delay death and prolong life), and number 25 (Only God can intervene in death). Participants in Type 2 with low factor weight were for number $14(Z=.06)$ and number 18 $(Z=.23)$. Number 14 stated that the patient's wishes should be reflected in choosing to painfully prolonging the life. Lower scores in Factor 1 statements reflected the belief that "death with dignity inevitable in certain circumstances."

Societal regulation of "death with dignity": There were 13 statements that were categorized as Type 3 (Table 3). The following are the descriptions of Q Classification interviews with students who displayed the characteristics of this type, assisted in understanding of the nature of this type. Number $12(\mathrm{Z}=1.45)$ and number $16(\mathrm{Z}=1.05)$ displayed a high level of factor weight. The statements with the highest level of agreement in Type 3 were number 3 (Life-prolonging treatment is a psychological burden on the patient and the family), number 2 ("Death with dignity" according to the will of a terminal patient should be accepted) and number 9 (Prior to permitting "death with dignity," definite criteria for its application must be set out). Thus the upper field of Factor 2 represented individuals advocating "societal regulation of death with dignity."

"Death with dignity" electivity: There were 13 statements that were categorized as Type 4 (Table 3). The statements with the high level of disagreement in Type 4 were number 39 ("Death with dignity" enhances the quality of life of a terminal patient), number 6 ("Death with dignity" only acknowledges medical treatment) and number 29 (The family of the patient can choose "death with dignity" even if treatment is an option). Participants in Type 2 with low factor weight were participant number $10(\mathrm{Z}=.22)$ and number $16(\mathrm{Z}=.22)$. Participant number 14 stated that patients and the parties involved may re-evaluate their views on "death with dignity" and should be able to change their opinions on it. Thus a low Factor 2 score reflected "death with dignity electivity."

"Death with dignity" criteria identification: There were 5 responses that were categorized as Type 5 (Table 3). The following are the descriptions of Q Classification 
interviews with nurses who displayed characteristics of this type, and assisted in understanding of the nature of this type. Number $21(\mathrm{Z}=.51)$ displayed a high level of factor weight. The statements with the highest level of agreement in Type 5 were number 2 ("Death with dignity" according to the will of a terminal patient should be accepted) and number 9 (Prior to permitting "death with dignity," definite criteria for its application must be set out). Thus the upper field of Factor 1 represented advocates for "identifying death with dignity criteria."

Preparing for "death with dignity": There were 5 statements that were categorized as Type 6 (Table 3). The statements with the high level of disagreement in Type 6 were number 44 (It is against the filial duty to delay death and prolong life), number 16Human life has absolute sanctity and discontinuing treatment cannot be justified in any way) and number 29 (The family of the patient can choose "death with dignity" even if treatment is an option). The participant in Type 6 with low factor weight was participant number $25(\mathrm{Z}=.15)$. Participant number 25 stated it was most important to respect the sanctity of life and define and prepare for "death with dignity" at the medical scene. Thus the lower field of Factor 2 denoted "preparing for death with dignity."

\section{Discussion}

This study was carried out with the aim of providing the baseline data for training programs analyzing cases of dying well or discontinuing life-prolonging treatments. This was through subjective data collection from nursing students on their attitude towards "death with dignity." Identifying the types and characteristics of the nursing students' attitudes towards "death with dignity" can have the nursing students become familiar with their role in treatment of terminal patients, and providing nursing mediation. This may also affect the level of efficiency in personnel and organizational management. This study identified the categories of nursing student attitudes towards "death with dignity" as "recognizing value in death with dignity," "inevitability of choosing death with dignity," "societal regulation of death with dignity," "death with dignity electivity," "death with dignity criteria identification" and "preparing for death with dignity," and the characteristics of each type are discussed below [9].

Type 1 attitude in this study was "recognizing value in death with dignity." Participants 22 and 29 who displayed a high level of factor weight stated that it was meaningful to think about the meaning of life and ponder over "death with dignity." Participant 4 stated that there was no value in meaningless extension of life.

Type 2 conclusion about "death with dignity" was that there was an "inevitability of choosing death with dignity." Participants 14 and 18 displayed a low factor weight, and stated that life-prolonging treatment was a high psychological and financial burden for the patient and the family, as there is a debate across society on "death with dignity."

Type 3 thought on "death with dignity" was the need for "societal regulation of death with dignity" procedure. Participants 12 and 13 who displayed a high level of factor weight stated that personal values should be reflected in "death with dignity" decisions, but value criteria of "death with dignity" should be established in the society.

Type 4 stance displayed by the nursing students was the "electivity of death with dignity." Participant 10 and 16 who displayed a low level of factor weight stated that individual opinions or choices across family or society should be considered. Those living in countries where "death with dignity" is not permitted sometimes choose to end their lives in countries, which permit the procedures.

Type 5 opinion on "death with dignity" was the importance of "death with dignity criteria identification." Participant 21 who displayed a high level of factor weight stated that it was important to live according to one's own will. Participant 21 also stated that making the decision for the patient on their own was also necessary. In this manner, people are thought to have the basic right to make a decision according to their free will 
and their own set of values for various situations, and the decisions made by them should be respected unless it breaches the rights of others [10].

Type 6 statement on "death with dignity" was the need for "preparing for death with dignity." Participant 25 who displayed a low level of factor weight stated that societywide awareness was necessary to have the various legal and institutional measures in place for such procedures.

The results of this study allowed a clear identification of types of attitudes held by nursing students towards "death with dignity."

\section{Conclusion}

The aim of this study was to identify and categorize the subjective attitude of nursing students towards "death with dignity." The findings will be able to assist in construction of training programs on "death with dignity" for nursing students and in addition, will be able to play a key role in identifying the attitude of nurses who work in departments in which they could face patients considering or in a situation to be considered for "death with dignity" when they become nurses after graduation. Also, the study was conducted in order to provide baseline data for development of educational and training programs on discontinuing life-prolonging treatment or palliative care through identifying the various opinions held by the nursing students towards "death with dignity" and analyzing the characteristics of each type. Based on the results of this study, the following suggestions are made: First, training programs will be required for nursing students or those in the medical profession that utilize a "death with dignity" checklist for each type categorized in this study. Second and last, a follow-up study will be required to more thoroughly examine and verify the differences of the types of thinking on situations for "death with dignity" as categorized in this study.

\section{References}

[1] H. N. Chu, "Possibilities of death with dignity and directions of its legislation", Journal of Forensic Science, vol. 21, no. 1, (2012), pp. 97-125.

[2] HTML Standard, http://terms.naver.com/entry.nhn?docId=630292\&cid=50766\&categoryId=50794 (2016).

[3] M.S. Han and B.H. Kim, "The meaning to death of cancer care nurse: Q-Methodological Application", Hanyang Journal Medical, vol. 19, no. 2, (1999), pp. 180-185.

[4] Y. H. Oh, "Set up legal and institutional device for death with dignity", Healthcare policy forum, vol. 6, no. 3, (2008), pp. 1-103.

[5] N. Moon, "A study on the moral foundation and measures of advance directive", Unpublished master's thesis, Dong-A University, Dong-A University, Busan, Korea, (2014).

[6] K. W. Jo, G. J. An, G. M. Kim and Y. J. Kim, "Predictive Factors for City Dwellers' Attitudes toward Death with Dignity", Korean journal of hospice and palliative care, vol. 15, no.4, (2012), pp. 193-204.

[7] Korean journal of hospice and palliative care, "Korean Nurses' Attitude towards Advance Directives and End of Life Decision Making", Journal of Korean critical care nursing, vol. 3, no. 2, (2010), pp. 77-90.

[8] S. M. Whang, S. W. You, J. Y. Kim and R. G. Kim, "Consumer Types and Cultural Consumption Characteristics of Korean Society: Who Spends for What Reasons?", Journal of Human Subjectivity, vol. 13, (2006), pp. 25-39.

[9] S. Jang and M. S. Wang, "Research on Subjectivity about Death with Dignity Perceived by Nursing Students Methodology", Proceedings of Asia-pacific Proceedings of Applied Science and Engineering for Better Human Life, Jeju, South Korea, (2016), vol. 10. 1-4.

[10] Y. S. Son, "Bioethics in Medicine", Journal of Korean bioethics association, vol. 11, no. 2, (2010), pp. 80 . 


\section{Authors}

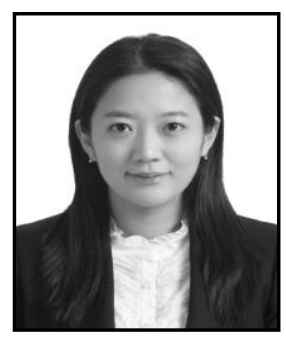

Sunyoung Jang, she received the $\mathrm{PhD}$ degrees in Nursing from Hanyang University, Seoul, South Korea in 2012. Currently, she is an assistant professor in Hanseo University, Seosan-si, South Korea. Her research areas include healthcare technology assessment, systematic review, meta-analysis, nurse-staffing and nursing management.

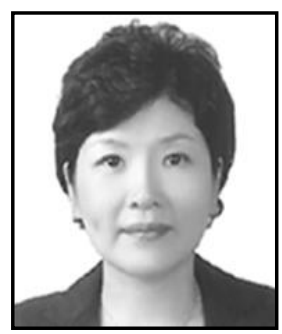

Meesuk Wang, she received the $\mathrm{PhD}$ degrees in Nursing from Hanyang University, South Korea in 2005. Currently, she is an assistant professor in Hanseo University, Seosan-si, South Korea. Her research areas include Women`s healthcare, Aged care, Clinical nurse. 